\title{
Loan-Portfolio Quality and the Diffusion of Technological Innovation *
}

\author{
Robert Hauswald \\ American University
}

\author{
Robert Marquez \\ University of Maryland
}

Current Version March 2004

JEL Classification: G21, L51, O31

\footnotetext{
${ }^{*}$ We would like to thank Haluk Unal for stimulating our interest in this area, and Rosalind Bennett, Andrew Davenport, Ulrich Hege, Dan Nuxoll, Michel Robe, and seminar participants at the FDIC and American University for suggestions that helped improve the paper. The research leading to this paper was undertaken while the authors were visiting the FDIC, whose hospitality and financial support is gratefully acknowledged. Part of this work was completed while Marquez was visiting the Wharton School of Business. The usual disclaimers apply. Contact information: Robert Marquez, R. H. Smith School of Business, University of Maryland, College Park, MD 20742, rmarquez@rhsmith.umd.edu, and Robert Hauswald, Kogod School of Business, American University, Washington, DC 20016,hauswald@american.edu.
} 


\title{
Loan-Portfolio Quality and the Diffusion of Technological Innovation
}

\begin{abstract}
We study the economic forces that drive innovation in credit-risk assessment and the role of regulators in fostering technological progress. Recent regulatory proposals base capital-adequacy standards on banks' own internal systems and call for regulators to establish a set of "best practices" for the industry. We find that the dissemination of innovations mandated by this approach generates a tension between lowering aggregate banking-system risk ex post and providing banks with incentives to innovate ex ante. Moreover, this tension arises purely from regulatory concern for bank safety and not from any interest in promoting competition. We show that achieving the optimal level of innovation requires that regulators restrict the diffusion of technology. If regulators are unable to commit to specific dissemination policies, it may be beneficial to let banks assert intellectual property rights through, for instance, the patenting of their innovations.
\end{abstract}




\title{
1 Introduction
}

Financial innovation has played an important role in shaping financial markets by extending their scope and increasing their efficiency (Van Horne, 1985). This is particularly true for financial intermediaries in the fields of risk measurement and risk management, where new analytic tools such as credit-scoring methodology, wider availability of data, better information processing (advances in IT), and new financial instruments such as credit derivatives have profoundly changed the nature of financial intermediation. ${ }^{1}$ The new regulatory standards commonly referred to as "Basel II" explicitly recognize this transformation for they base each bank's capital requirement on the riskiness of its portfolio as assessed by its own, often proprietary, systems. In this paper we analyze the economic forces that drive financial innovation in credit risk management, and the role played by regulators in fostering such advances.

Such an analysis is of primary importance in light of recently proposed changes to the regulatory framework that give supervisors and regulators direct responsibility for encouraging the development of risk-management systems through the supervisory review of banks' internal risk-assessment models. Moreover, as a way of reducing risk in the banking system, these proposals mandate establishing a set of industry "best practices" and distributing any newly developed methodologies to all banks. ${ }^{2}$ Recent comments on Basel II by Federal Reserve Board Governor Laurence H. Meyer summarize this role for supervisors: ${ }^{3}$

\begin{abstract}
"We're not smart enough in Washington to figure out what the best practices are for banks, but we are smart enough to ask banks what they're doing and to identify what best practice is and then to spread it around."
\end{abstract}

We point out that there is an inherent tension between the development of effective riskassessment tools by banks and the diffusion of such technology by regulators. Any diffusion policy aimed at reducing banking-system risk must therefore balance the ex post benefits of widely adopting financial innovations with the ex ante protection of the innovator's intellectual property rights

\footnotetext{
${ }^{1}$ See Mishkin and Strahan (1999) or Allen, McAndrews and Strahan (2002) for a description of these trends, and Hauswald and Marquez (2003) for a formal analysis.

${ }^{2}$ The new "internal-risk based" capital standards place heavy emphasis on proprietary risk-management practices, especially in the area of credit risk. For details, see BIS (2003a) and, especially, the discussion of "Pillars 1 and 2" of the Basel II Proposal. Hirtle et al. (2001) discuss the regulatory challenges of this approach.

${ }^{3}$ Interview published in ABA Banking Journal, September 2001, p. 43.
} 
so as to preserve the incentives for innovation.

To study these issues, we present a model in which two banks compete for borrowers by screening loan applicants and making loan-rate offers in each of two periods. In the first period, one bank, a "technology leader," invests in the development of a technology for credit-risk assessment and uses the results of its credit screens to compete against an uninformed intermediary. Improvements in the technology for assessing credit risk allow lenders to better sort borrowers and thereby avoid extending loans to applicants that are not creditworthy. In the second period, the uninformed bank acquires this technology with a certain probability that is set by bank regulators and that depends on stated dissemination policy. If such diffusion takes place, both banks acquire information before competing for borrowers; otherwise, the technology leader competes against an uninformed intermediary as in the first period.

We find that the technology leader's investment in developing financial innovations decreases in the probability of diffusion of these innovations as well as in the average creditworthiness of borrowers. Since the price of a loan is competitively set, the diffusion of technological advances puts both banks on a more-equal footing and leads to more aggressive bidding for borrowers in the second period. This increase in competition lowers the price of the loan and reduces the overall returns to investments in technology, thus decreasing the technology leader's incentive to innovate. Similarly, increases in the average creditworthiness of borrowers reduce overall credit risk and therefore the necessity for screening, again making lending markets more competitive and lowering the innovating bank's investment.

Although financial regulators typically have a wide array of responsibilities, we focus on their role in minimizing credit risk in the banking system. To this end, regulators choose the probability of technological diffusion after the technology leader has innovated. Our main result establishes that regulators should restrict the extent to which they disseminate the technology so as to partially protect the informational monopoly created by the leader and encourage financial innovation. Although ex post the aggregate loan-portfolio quality of the banking system increases in technological diffusion, regulators may wish to respect intellectual property rights to provide ex-ante incentives for financial innovation.

However, such a regulatory approach presupposes that regulators can credibly commit to announced diffusion policies. Such commitment may not be feasible, given the evolving regulatory 
framework and political pressures that mandate the establishment of best practices in credit-risk assessments. Also, regulators themselves may wish to standardize risk-assessment techniques through dissemination in order to facilitate the supervisory function. Since the ex-post expropriation of proprietary technology leads to suboptimal levels of financial innovation and increased aggregate loan-portfolio risk, it might be in both the regulators' and the technology leader's best interests that banks take steps to assert their intellectual property rights over financial innovations through, for instance, patenting (see Lerner, 2002). We find that, despite limiting competitors' ability to make use of innovations, some activity on the part of the innovating bank to protect its technology is always beneficial in the sense of both increasing the extent of innovation and reducing aggregate portfolio risk. Moreover, regulators may wish to resort to other devices, such as less frequent audits or greater regulatory leniency, as additional ways of rewarding innovators.

Our main contribution is to establish the existence of a trade-off between individual bank profitability driven by financial innovation and overall banking-system risk. When one bank improves the quality of its credit screen, it is able to reduce its own portfolio risk by avoiding loans to borrowers that are not creditworthy and to raise its profits by increasing its information advantage vis-à-vis other lenders. Similarly, the dissemination of improvements in credit screening and their adoption by competitors lowers the overall credit-risk exposure of the banking system. However, putting all banks on a more-level playing field increases competition, thereby reducing the profitability of the innovating bank and hurting its incentive to innovate in the first place. It is this trade-off between risk-reducing diffusion of technology and the profitability of investments in innovations that is at the heart of our analysis.

To the best of our knowledge, the role of regulation in fostering financial innovation, its diffusion, and the protection of intellectual property rights in this area has been little studied. An exception is White (1997), who surveys public-policy issues arising from the interdependence of regulation and financial innovation. Instead, the analysis of financial innovation has traditionally focused on new products and financial instruments (see, e.g., Tufano, 1989 and 2002) rather than on business processes and methodology, which are central to our analysis. For example, Merton (1995) examines the regulatory challenges posed by product innovation.

Closer to our work are Bhattacharyya and Nanda (2000), who study the incentives investment banks have to innovate as a function of client characteristics and market structure, and Anand 
and Galetovic (2000), who investigate banks' incentives to preserve their private information in the presence of weak property rights. Concerning intellectual property rights over financial innovations, Lerner (2002) studies the growing importance of financial patents, while Herrera and Schroth (2003) analyze the incentives for developing financial instruments in the absence of explicit patent protection in a setting similar to ours, in which the innovating party takes steps to protect its intellectual property. In a similar vein, Anton and Yao (2002) analyze how the strength of intellectual property rights affects firms' incentives to patent innovations or to rely instead on secrecy in order to keep these innovations private. Our analysis focuses on the incentive effects of regulatory policy that would force proprietary technology into the public domain.

Furthermore, this paper is clearly related to the broader question of R\&D incentives and the diffusion of innovations (see Reinganum, 1989 or Tirole, 1988 for surveys). In particular, our analysis identifies a trade-off for policy makers similar to that known from the literature on the patenting of innovations that studies the conflict between promoting competition by making innovations widely available, and fostering technological progress by allowing firms to retain ex post monopoly power over their discoveries. For example, Benoît (1985) studies innovation and imitation in a duopoly when a technology leader enjoys a timing advantage as in our model, but the paper does not address the public policy issues that are our focus. A distinguishing feature of our approach is that, unlike in the $\mathrm{R} \& \mathrm{D}$ literature, the regulators' objective in our model is not to promote competition per se, but rather to reduce credit risk in the banking system. However, regulatory actions taken to reduce risk have the side effect of enabling banks to compete more effectively with the technology leader through the wider adoption of innovations. Although the resulting trade-off resembles that found in the R\&D literature, it stems purely from regulatory concerns about bank risk rather than from loan-market competition.

The paper is organized as follows. In the next section, we discusses in more detail the role of supervisors under the Basel II proposal before describing the model in Section 3. Section 4 derives the lending equilibria and examines banks' technological investments. In Section 5, we characterize the aggregate loan-portfolio risk and analyze the regulators' decision problem. Section 6 studies the incidence of protecting intellectual property rights when regulators are unable to commit to not expropriate the innovation. Section 7 discusses further implications and possible extensions. Proofs are mostly relegated to the Appendix. 


\section{Risk Assessment and Regulation}

The Basel II regulatory standards that are to be finalized by mid-2004 and are scheduled to come into force by 2007 comprise three distinct "pillars:" risk-based capitalization standards, supervisory validation of banks' risk-assessment methods, and public disclosure and market discipline. Our focus is primarily on the second and third pillar that ascribe a crucial role to regulators in identifying best practices in risk assessment and management and in disseminating them with a view to creating industry-wide standards.

The recent Third Quantitative Impact Study (BIS, 2003b) reveals that capitalization standards under the most advanced internal risk-based systems provide powerful incentives for banks to invest in the development of such proprietary technology. Under Pillar 1 ofthe proposed Basel II rules, 65 large, global banks ("G10 banks" of the standard-setting countries) would be able to decrease their capitalization by $2 \%$ under advanced systems, whereas their capitalization would have to increase by $11 \%$ if they used the standardized (nonproprietary) default risk-rating system. For a similar group of large EU banks, capitalization requirements would decrease by $6 \%$ under proprietary systems for (credit) risk assessment that conform to the "Advanced" standard, but would increase by $6 \%$ under the standardized approach. Furthermore, the proposed rules give regulators an explicit role in validating proprietary systems and disseminating best practices in risk management (Pillars 2 and 3$)$.

The Basel II Agreement poses the following quandary for regulators and supervisors. On the one hand, Pillar 1 (risk-based capital-adequacy standards) presupposes that banks invest in technology for credit-risk assessment and, indeed, provides strong incentives for them to do so. On the other hand, the wide dissemination of credit-risk assessment models for validation purposes and to speed up the adoption of best practices would make the new rules more effective, in particular Pillars 2 (supervisory validation) and 3 (public disclosure and market discipline). It would also standardize risk-management practices, facilitating future bank audits.

However, the dissemination of proprietary technology to competitors might hurt incentives to innovate. The Basel II proposal recognizes this inherent dilemma but offers little guidance on how regulators might resolve it: ${ }^{4}$

\footnotetext{
${ }^{4}$ BIS (2003a): paragraph 768, p. 156.
} 
"Proprietary information encompasses information (for example on products or systems), that if shared with competitors would render a bank's investment in these products/systems less valuable, and hence would undermine its competitive position. ... This has an impact on what banks should reveal in terms of ... details on their internal arrangements, for instance methodologies used, parameter estimates, data etc. ... In exceptional cases, disclosure of [proprietary or confidential] information required by Pillar 3 may prejudice seriously the position of the bank."

Hence, it is unclear how regulators should act in the face of public and political pressures to render the banking system safer through the wide dissemination of best practices in risk management. As Hirtle et al. (2001) observe, ${ }^{5}$ the benefits of such disclosure have to be weighed against its cost in terms of foregone incentives to innovate. In essence, the question reduces to finding a balance between disclosure, dissemination, and the protection of intellectual property rights.

\section{Model Description}

Let there be a continuum of potential borrowers of measure 1 that can be either of high or low credit quality $\theta \in\{l, h\}$, with each type being equally likely. In each of two periods, these borrowers have an investment project lasting one period that requires an initial outlay of $\$ 1$, but have no private resources. The project of a high-quality borrower $h$ yields a terminal cash flow $R$ with probability $p_{h}>0$ and 0 with probability $1-p_{h}$, while that of a low-quality borrower $l$ returns 0 with certainty. The success probability of projects is independent across borrowers, and each project is independently and identically distributed across both periods. ${ }^{6}$ Letting $\bar{p} \equiv \frac{1}{2} p_{h}$ denote the average repayment probability, we also assume $m<\bar{p} R<M$ for some $M>m>1$, so that it

\footnotetext{
5 "Another approach to model validation ... would be to require all banks using internal models for regulatory capital purposes to disclose publicly full documentation of the model's mathematical structure, key assumptions, and parameter estimates. ... This scrutiny could aid the supervisory validation process by providing independent assessments of a bank's model by market practitioners and interested academics. In addition, it could improve modeling practices for the industry as a whole by ensuring that the latest modeling innovations were quickly disseminated to all practitioners... . The benefits of public disclosure would also have to be weighed against their potential costs, including the possibility that mandatory disclosure would undercut banks' incentives to develop new and innovative modeling practices, since they would have to share the benefits of any innovations with their competitors" (p. 31).

${ }^{6}$ Alternatively, we could assume that there is sufficient turnover among borrowers so that credit-quality information is not reusable across time. The assumption that projects are independent allows us to focus solely on the consequences of technological diffusion and ignore any issues arising from portfolio diversification.
} 
is ex ante efficient to grant a loan. ${ }^{7}$ Final cash flows are observable and contractible, but borrower type $\theta$ is unknown to either borrower or lender.

Two banks compete for borrowers in this market over the two periods. In the first period, bank 1, which we will call the technology leader (or informed bank), must decide how much to invest in developing a screening technology $\phi$ that generates borrower-specific information. The development of this technology represents the financial innovation in our model. The other intermediary, bank 2 , does not yet have access to such technology and therefore remains uninformed. Regulators commit to a dissemination policy by setting a probability $\lambda$ with which the screening technology $\phi$ will be made available to bank 2 in the second period. We later relax this assumption and study the case when such commitment is not possible.

Screening of borrowers leads to better credit assessments that provide banks with an informative signal about a loan applicant's type. In particular, credit screens yield a signal $\eta \in\{l, h\}$ about the borrower's repayment probability ${ }^{8}$ with the probability of successful and erroneous credit assessments given by, respectively,

$$
\begin{aligned}
& \operatorname{Pr}(\eta=h \mid \theta=h)=\phi=\operatorname{Pr}(\eta=l \mid \theta=l) \\
& \operatorname{Pr}(\eta=h \mid \theta=l)=1-\phi=\operatorname{Pr}(\eta=l \mid \theta=h)
\end{aligned}
$$

The quality or informativeness of the credit screen is therefore given by $\phi$. Credit analysis is not perfect and depends on the costly technology investment by bank 1, the technology leader. For concreteness, we assume that this cost is quadratic in the quality of the technology so that the technology leader spends $c(\phi)=\left(\phi-\frac{1}{2}\right)^{2}$ on acquiring and developing the screening technology with precision $\phi$.

Figure 1 summarizes the model's time structure. In the first period, the technology leader decides how much to invest in the screening technology. This investment is observable so that all parties know the quality $\phi$ of the technology but not the outcome of any particular credit screen

\footnotetext{
${ }^{7}$ The restriction $\bar{p} R<M$ ensures that banks do not wish to lend to a borrower with a negative credit assessment. If $\bar{p} R$ is very high so that the average return to lending is large, lenders may choose to ignore information from their credit screens and just lend to all borrowers. We derive a specific numerical value for $M$ in the proof of Proposition 3 in the Appendix. The assumption $\bar{p} R>m$ guarantees sufficient investment in the screening technology that its dissemination is beneficial ex post (see the proof of Lemma 3 for details).

${ }^{8}$ An alternative specification yielding similar results would be to assume that borrowers post collateral and banks develop costly expertise in assessing its value. According to Allen, DeLong and Saunders (2004), most creditscoring models sort borrowers and their collateral into "good" and "bad" risks. This binary classification guides our specification for the screening technology.
} 


\begin{tabular}{|c|c|c|c|}
\hline \multicolumn{2}{|r|}{$t=1$} & \multicolumn{2}{|c|}{$t=2$} \\
\hline Start of 1 & End of 1 & Start of 2 & End of 2 \\
\hline $\begin{array}{l}\text { Investment } \phi \\
\text { Screening: } \eta\end{array}$ & $\begin{array}{c}\text { Loan-rate offers } \\
\text { Borrowers choose bank }\end{array}$ & $\begin{array}{l}\text { Dissemination with prob. } \lambda \\
\text { Screening: } \eta \text { or }\left(\eta_{1}, \eta_{2}\right)\end{array}$ & $\begin{array}{l}\text { Loan-rate offers } \\
\text { Borrowers choose bank }\end{array}$ \\
\hline
\end{tabular}

Figure 1: Time Structure of the Model

by bank 1 . Both banks then compete by simultaneously making interest rate offers, bank 1 on the basis of the outcome of its credit screen, $\eta$, and bank 2 without proprietary information. Borrowers choose last by accepting a loan from the bank quoting the lowest rate.

At the beginning of the second period, borrowers apply for loans to finance new projects and regulators disseminate the screening technology with probability $\lambda$. In this case, both banks screen loan applicants and obtain conditionally independent creditworthiness assessments. On the basis of these assessments $\left(\eta_{1}\right.$ and $\left.\eta_{2}\right)$, both banks make simultaneous loan offers. If bank 2 does not acquire the screening technology, which occurs with probability $1-\lambda$, the banks compete by quoting loan rate offers as in the first period. Borrowers again act last by choosing the bank with the lowest rate. For simplicity, we normalize the banks' cost of funds and discount rates to 0 .

\section{Lending Competition and Financial Innovation}

In this section, we characterize the competition for borrowers between intermediaries and analyze the technology leader's optimal investment in technological innovation.

\subsection{Credit-Market Competition}

We first derive the equilibria in the two possible lending subgames in period 2, starting with the case in which bank 1, the technology leader, competes for borrowers against an uninformed bank. The technology leader's strategy has two components: its investment in developing the screening technology, and its loan offer, which can be conditioned on the results of the credit assessment. The uninformed bank, by contrast, has no information and can decide on its loan offers knowing only that bank 1's credit screen provides it with information of quality $\phi$, but not the actual outcome of such screening.

Let $\pi_{1}(\eta)$ represent the expected profits from a loan, gross of the innovation cost $c(\phi)$, of bank 
1 after observing a creditworthiness signal $\eta \in\{h, l\}$ and $\pi_{2}$ the profit of bank 2 in the first period. We next characterize the equilibrium in the lending subgame in which banks 1 and 2 compete in loan-rate offers, after the former has made its investment decision.

Proposition 1 There exists a unique equilibrium in mixed strategies between asymmetrically informed banks in which the uninformed lender (bank 2) bids with probability $\beta(\phi)<1$.

The equilibrium expected profits prior to the observation of the signal, and gross of the cost of investment, are positive for the technology leader (bank 1) and zero for bank 2:

$$
\begin{aligned}
E\left[\pi_{1}(\eta)\right] & =\frac{1}{2}(2 \phi-1) \\
E\left[\pi_{2}\right] & =0
\end{aligned}
$$

Proof. See Appendix.

The fact that no pure strategy equilibrium exists when bidders have asymmetric information is well-known (see von Thadden, 2001, and Engelbrecht-Wiggans et al., 1983) and a simple consequence of the winner's curse. Any predictable strategy by the uninformed bank would surely be undercut by bank 1 , which would simply make better offers to borrowers deemed of higher quality, leaving bank 2 to finance all bad risk.

The proposition also shows that we obtain a very simple expression for expected profits to a technology leader that is linear and increasing in the quality of the screening technology $\phi$. The comparative-statics properties of expected profits are very intuitive: since an informed intermediary enjoys a greater informational advantage over its competitors, the uninformed bank faces a larger adverse-selection problem and bids less aggressively. Consequently, the technology leader earns higher profits on those borrowers with good signals.

We next consider the second case, in which the technology has indeed been disseminated and is available to both intermediaries. Two informed banks now compete against each other on the basis of conditionally independent credit screens $\eta_{i}, i=1,2$, of the same informativeness $\phi$. Again, there only exists a unique equilibrium in mixed strategies.

Proposition 2 In the lending game between banks carrying out conditionally independent credit screens of the same informativeness $\phi$, there exists a unique symmetric mixed-strategy equilibrium. 
For $\phi \geq \underline{\phi} \equiv \frac{p_{h} R-1}{p_{h} R}$, equilibrium expected profits before observation of the signal for bank $i=1,2$ are given by

$$
E\left[\pi_{i}\left(\eta_{i}\right)\right]=\phi(1-\phi)(\bar{p} R-1)
$$

Proof. See Appendix.

The profit function highlights the particular nature of competition for borrowers between banks whose information is private but symmetric in its quality. Although the threat of adverse selection after observation of the signals still allows banks to extract information rents, they cannot capture more than the expected average net return on a loan weighted by the variance of a correct credit assessment. Profits are now decreasing in the signal quality $\phi$ and increasing in the average repayment probability of borrowers $\bar{p}$. The first comparative-statics property reflects the effects of Bertrand competition, as more-informative credit screens reduce the threat of adverse selection, allowing banks to bid more aggressively but eroding their information rents. The second property corresponds to the informational capture of high-quality borrowers because the average repayment probability is a function of the high-quality borrower's success probability: $\bar{p}=\frac{1}{2} p_{h}$. The condition $\phi \geq \underline{\phi}$ guarantees that credit assessments are of sufficient quality to rule out lending to applicants with low credit assessments. Below we verify that this condition is always satisfied in equilibrium so that Equation (3) is well specified.

\subsection{Technological Innovation}

We next consider the technology leader's decision to invest in developing financial innovations in the form of the screening technology. Let superscripts index time periods $t=1,2$. In the first period, since bank 1 is the only one possessing the screening technology, its net profits are simply the expression in Equation (2) minus the cost of acquiring the technology. In the second period, bank 2 acquires the credit assessment technology with probability $\lambda$ so that, letting $\pi_{i}^{t}$ denote the profit of bank $i$ in period $t$, bank 1's profits are

$$
E\left[\pi_{1}^{2}\right]= \begin{cases}\phi(1-\phi)(\bar{p} R-1) & \text { with probability } \lambda \\ \frac{1}{2}(2 \phi-1) & \text { with probability } 1-\lambda\end{cases}
$$


Letting $\Pi_{1}$ represent profits net of innovation costs, bank 1's ex-ante expected net profits are

$$
E\left[\Pi_{1}\right]=(2-\lambda) \frac{1}{2}(2 \phi-1)+\lambda \phi(1-\phi)(\bar{p} R-1)-\left(\phi-\frac{1}{2}\right)^{2}
$$

From the preceding expression, we can now establish the following result:

Proposition 3 The technology leader's optimal investment in screening technology is given by

$$
\phi^{*}=\min \left\{\frac{3+\lambda(\bar{p} R-2)}{2+2 \lambda(\bar{p} R-1)}, 1\right\}
$$

Credit screens are sufficiently informative that borrowers with low credit-quality assessments do not obtain loan offers: $\phi^{*} \geq \underline{\phi}>\frac{1}{2}$.

Proof. See Appendix.

Proposition 3 derives the optimal (profit-maximizing) investment in developing the risk-assessment technology given a particular dissemination policy $(\lambda)$ of financial innovations. The constraint that $\phi^{*} \leq 1$ reflects the fact that, since $\phi$ represents the probability that the result of the credit assessment is correct, it cannot be greater than one.

The optimal level of innovation exhibits intuitive comparative-statics properties:

Corollary 1 For $\phi^{*}<1$, the optimal innovation investment decreases in the average repayment probability $\bar{p}$ and in the probability of technology diffusion $\lambda: \frac{\partial \phi^{*}}{\partial \bar{p}}<0$ and $\frac{\partial \phi^{*}}{\partial \lambda}<0$.

Proof. $\frac{\partial \phi^{*}}{\partial \bar{p}}<0$ follows by differentiating Equation (5) with respect to $\bar{p}$, and observing that $\lambda \leq 1$. The second result is obtained similarly, since $\frac{\partial \phi^{*}}{\partial \lambda}=-\frac{2 \bar{p} R-1}{2[1+\lambda(\bar{p} R-1)]^{2}}$ is negative by $\bar{p} R>1$.

As the average repayment probability $\bar{p}$ increases, it becomes less necessary to screen borrowers in order to avoid adverse-selection problems. At the same time, a rise in the average repayment probability increases competition for borrowers, further reducing banks' incentives to invest in the screening technology. Similarly, if the probability of technological diffusion $\lambda$ increases, technology leaders are less likely to fully appropriate the gains from their innovations in the second period, and the overall expected return and investment in screening decrease. ${ }^{9}$

\footnotetext{
${ }^{9}$ All results above continue to hold if we assume that low-quality borrowers have positive NPV projects but with a lower success probability than high-quality borrowers. An informed bank would then offer credit at the break-
} 
It is worth noting that, although we arbitrarily ascribed the role of technology leader to bank 1, we could endogenize this choice without qualitatively changing our results by assuming, for instance, that banks enter into an $\mathrm{R} \& \mathrm{D}$ race to determine which one successfully innovates. In practice, financial markets tend to have natural leaders in the development of technology. For example, empirical evidence by Akhavein, Frame, and White (2003) suggests that, in the context of credit-risk assessment, it is primarily large banks that lead the industry in developing innovations.

\section{Portfolio Risk and Technological Diffusion}

We first analyze the effect of technological diffusion on the average portfolio quality of the technology leader. To this end, define $p(h)$ as the post-screening success (and hence repayment) probability of borrowers in the case of a high-quality credit assessment $\eta=h$, which also corresponds to bank 1's loan-portfolio quality in the first period.

Lemma 1 In equilibrium, the average repayment probability of the technology leader's loan portfolio in the first period decreases in the likelihood of diffusion of the innovation in the second period: $\frac{\partial p(h)}{\partial \lambda}<0$.

Proof. See Appendix.

A higher probability of technological diffusion means that bank 1 is more likely to face competition from an informed intermediary in the second period. As a result, it cuts back its investment in technology and financial innovation. This reduction in $\phi$, however, hurts the quality of its screening process and, hence, worsens its average loan-portfolio quality, as measured by the post-screening repayment probability of borrowers with high-quality signals. Despite the fact that bank 1 enjoys an informational monopoly in the first period, its reduced ability to recover high R\&D investments over two periods hurts the initial development of credit-assessment systems.

The diffusion probability $\lambda$ also affects the competitive intensity of the credit market as measured by the probability $\beta(\phi)$ that the uninformed bank bids in the first period.

even interest rate to borrowers deemed of low-quality and, as in the preceding analysis, an uninformed bank could never earn positive profits. Incorporating this alternative specification complicates the notation without yielding any additional insights. 
Lemma 2 The probability of a competing loan offer by bank 2 in the first period increases in the diffusion probability, i.e., $\frac{\partial \beta}{\partial \lambda}>0$.

Proof. See Appendix.

The higher the probability of disseminating the credit-assessment technology, the less the technology leader invests in its development (Corollary 1), and the less severe the adverse-selection problem becomes for the uninformed bank. As bank 1's technological and therefore informational advantage decreases, bank 2 is able to bid more aggressively and more frequently for borrowers.

\section{$5.1 \quad$ Regulatory Objective}

In our model, financial regulators have as their objective the reduction of credit risk in the banking system, or, equivalently, they seek to maximize loan-portfolio quality by choosing the rate of technological diffusion $\lambda .{ }^{10}$ In deciding on the optimal propagation of technological and financial innovation, regulators face the following trade-off: once sufficient technological progress has occurred, adopting a policy of widely diffusing best practices in credit assessment (and risk management), corresponding to a high value for $\lambda$, clearly benefits the banking system and its customers. At the same time, such a policy destroys the ex ante incentives of technological leaders to invest in the screening technology and financial innovation (Corollary 1).

We are now ready to state the overall banking system's portfolio risk in the second period and study the regulator's diffusion of technological innovation. In the second period, the banking sector's expected loan-portfolio quality, as measured by the aggregate loan-repayment probability, is

$$
P^{2}=\lambda \tilde{p}+(1-\lambda) \widehat{p}
$$

where $\tilde{p}$ is the expected success probability of a borrower obtaining financing when both banks have access to the technology and use it to screen, and $\widehat{p}$ is the analogous probability if only bank 1 uses

\footnotetext{
${ }^{10}$ In practice, bank regulators may have a number of additional responsibilities and objectives. Our only requirement is that some concern about credit risk enter regulators' objective function. By using this simplified regulatory objective, we isolate the implications for technological diffusion that arise purely as a consequence of concerns along this dimension.
} 
the screening technology. These success (repayment) probabilities are given, respectively, by

$$
\begin{aligned}
& \tilde{p}=\operatorname{Pr}(\theta=h \mid \text { offer }) p_{h}=\frac{2 \phi-\phi^{2}}{2 \phi+1-2 \phi^{2}} p_{h} \\
& \widehat{p}=\frac{\operatorname{Pr}(\text { bank } 2 \text { bids }) \bar{p}+(1-\operatorname{Pr}(\text { bank } 2 \text { bids })) \operatorname{Pr}(\eta=h) p(h)}{\operatorname{Pr}(\text { offer })}=\frac{\beta+(1-\beta) \phi}{1+\beta} p_{h}
\end{aligned}
$$

where $\operatorname{Pr}(\theta=h \mid$ offer $)$ is the probability that a loan applicant who has received an offer is actually of high quality.

Regulators maximize the banking system's aggregate loan-repayment probability in the second period given by Equation (6) or, equivalently, they minimize the aggregate credit-risk exposure. This objective function is motivated by our interest in the long-term effect of regulatory diffusion on overall credit risk, for which the first period is simply a transitional phase, as the dissemination of new technology can only occur in the second period. The objective function therefore represents a weighted average of two market structures, one in which bank 1 has sole use of the new technology and one in which both banks can make use of it. ${ }^{11}$

Before investigating the optimal amount of technological diffusion, we note the following result:

Lemma 3 For a given $\phi$, the expected aggregate loan-portfolio quality in the second period $P^{2}$ increases in $\lambda$, the rate of diffusion.

Proof. See Appendix.

The intuition for this result is fairly straightforward. Once the screening technology $\phi$ has been developed, supervisors can improve the banking system's overall portfolio quality by disseminating the innovation as widely as possible, so that both banks reduce the number of low-quality loans granted. In other words, wider availability and adoption of the improved technology reduce aggregate portfolio risk in the banking system.

It is worthwhile noting that, although we cast the regulatory objective in terms of maximizing loan-portfolio quality, this formulation is equivalent to the maximization of aggregate surplus from

\footnotetext{
${ }^{11}$ Incorporating a regulatory concern for loan-portfolio quality in the first period does not change the results in any qualitative way. Since the average success probability of borrowers obtaining financing in the first period is just $\widehat{p}$, the regulator's objective function becomes (ignoring any discounting across periods)

$$
\widehat{p}+\lambda \tilde{p}+(1-\lambda) \widehat{p}=\lambda \tilde{p}+(2-\lambda) \widehat{p}
$$
}

yielding almost identical results. 
lending. To see this, note that since $R$ is the payoff from a successful project and $P^{2}$ the aggregate success probability of funded projects, aggregate surplus is given by $P^{2} R-1$. Furthermore, our specification is also consistent with a model in which regulators minimize the probability of bankingsystem failure when there is a finite number of borrowers. In that setting, the probability of failure is monotonically decreasing in the aggregate portfolio quality $P^{2}$, so that maximizing $P^{2}$ is equivalent to minimizing failure probability.

\subsection{Optimal Dissemination Policy}

In setting a policy of propagating best practices in credit-risk measurement and management, regulators choose $\lambda$ to maximize $P^{2}$, aggregate loan-portfolio quality, subject to the technology leader's optimal investment in innovation:

$$
\begin{aligned}
& \max _{\lambda \in[0,1]}\{\lambda \tilde{p}+(1-\lambda) \hat{p}\} \\
& \text { subject to } \phi(\lambda) \in \underset{\phi}{\arg \max } E\left[\Pi_{1}\right]
\end{aligned}
$$

where $E\left[\Pi_{1}\right]$ is the ex-ante expected net profit of bank 1 given in Equation (4).

Proposition 4 The banking sector's expected loan-portfolio quality is maximized by setting $0<$ $\lambda^{*}<1$, i.e., by choosing less-than-perfect diffusion of innovation.

Proof. See Appendix.

The result states that, if regulators can choose the amount of diffusion of technological progress so as to maximize the quality of banks' portfolios, they will not fully disseminate innovations because they must trade off two different effects. First, they must choose a level of $\lambda$ sufficiently high that bank 2 is sometimes able to acquire the technology and can avoid making loans to some low-quality borrowers. By having both banks screen more efficiently, regulators are able to reduce the overall portfolio credit risk. However, a consequence of the diffusion of technology is that it also levels the playing field, leading the two intermediaries to compete on a more equal basis for borrowers in the second period.

In particular, if $\lambda$ is too high, the ensuing competition will reduce bank 1's profits as both intermediaries use technology of the same quality to assess credit risk. This reduction in profits 
for the technology leader in period 2 decreases its incentive to invest in developing the technology in the first period, leading to less-informative credit assessments (lower $\phi$ ). Moreover, regulators cannot easily substitute for banks in the development of new technology, for they have neither the profit incentive nor the expertise to produce financial innovations. The optimal dissemination policy trades off these two forces and sets a rate of diffusion that still provides sufficient incentives for bank 1 to innovate.

It is worthwhile to point out that the interior solution is a consequence purely of regulatory concerns and not the result of any direct costs stemming from the dissemination of financial innovations. To the extent that such additional costs enter into regulatory considerations, their inclusion in the objective function would further restrict the dissemination of technology. Furthermore, while $\lambda$ formally represents the probability of technological diffusion, we could also interpret it as the extent to which regulators disseminate any given innovation. A dissemination policy of $\lambda<1$ would then correspond to partial dissemination, such as only describing the methodology or making a fraction of the risk-assessment system publicly available. Our results go through under this alternative interpretation.

While we have focused on innovations introduced by banks, third-party vendors, such as Fair Isaac, KMV, or Murex to name a few, also supply sophisticated risk-management tools to the industry. These vendors do not directly compete with banks, nor are they subject to supervisory action and are therefore not subject to regulatory expropriation of their technology. Incorporating the possibility of financial innovation by third parties, however, does not change the qualitative conclusions of our analysis. Even with off-the-shelf risk-assessment solutions banks have an incentive to invest in differentiating these basic tools and in developing their own models in order to gain a competitive edge in the pricing of loans and in the managing of credit risk, thus allowing them to realize higher profits. Hence, banks innovate precisely so as not to rely on the same systems as everyone else. ${ }^{12}$

\footnotetext{
${ }^{12}$ The Basel II proposal actually envisions three categories for credit-risk systems with varying degrees of differentiation (see BIS, 2003a): (1) the Standardised Approach (uniform systems supplied by national regulators), (2) the Foundation Internal-Risk Based Approach (semi-proprietary systems), and (3) the Advanced Internal-Risk Based Approach (fully proprietary systems).
} 


\section{The Role of Commitment}

Implementing the optimal rate of technological diffusion presupposes that regulators can commit to specific policies in this regard. Otherwise, innovating banks will anticipate the full dissemination of their technological advances and choose their investment in screening technology accordingly. We analyze in this section the effect of the absence of regulatory commitment and propose alternative mechanisms to protect banks' intellectual property rights.

\subsection{Full Dissemination}

Lemma 3 highlights the problem that regulators face in setting regulatory policy. Once financial innovations have taken place, overall portfolio quality will improve if all banks adopt such technological advances. Ex post (in period 2), regulators always have an incentive to choose a rate of diffusion as high as possible to minimize the banking sector's aggregate credit-risk exposure.

In the absence of some commitment device, the technology leader will expect regulators to set the diffusion rate $\lambda$ to its maximum value in period 2. However, from Proposition 3 and Corollary 1, we have, for $\lambda=1, \phi^{*}(1)=\frac{\bar{p} R+1}{2 \bar{p} R}<\phi^{*}\left(\lambda^{*}\right)$, whereas Proposition 4 establishes that aggregate loan-portfolio quality is maximized by some rate of diffusion $\lambda^{*}<1$. Hence, full dissemination hurts ex ante incentives to innovate more than it improves ex post loan-portfolio quality.

The fact that complete diffusion of technological advances decreases overall loan-portfolio quality points to the balance that regulators must strike in light of the Basel II Agreement. However, once such a balance is found, for instance, in the form of an optimal disclosure rate $\lambda^{*}$, one still needs to translate this objective into a workable regulatory policy. We now turn to possible commitment mechanisms for regulators and alternative arrangements that would allow banks to retain some measure of control over the technology they developed.

\subsection{Rewarding Innovators}

In practice, typical commitment devices such as dissemination standards or mandatory compensation may not be workable because they are subject to unilateral redefinition or impossible to verify by a third party, such as a court of law. In such situations, regulators may instead choose to reward innovating banks through regulatory or supervisory actions. Such rewards could take the form of 
less interference or more leniency in terms of allowing banks to enter new geographic or product markets.

In our model, financial innovation improves the technology leader's loan-portfolio quality. Hence, one possible commitment mechanism is to tie the frequency of bank audits to the quality of creditassessment systems, with the less-frequent supervisory review for banks with better systems. Such a policy is not only justified by the higher loan-portfolio quality but also offers the technology leader a grace period to benefit from any innovations. In addition, it reduces the dissemination of knowledge throughout the regulatory community, thereby decreasing the likelihood of diffusion even further. Indeed, this logic is reflected in the current practice of auditing banks with strong CAMEL ratings less frequently, which reveals an explicit link between established regulatory policy and loan-portfolio quality. ${ }^{13}$

However, one of the drawbacks of rewarding innovation through more lenient supervision might be to increase risk taking in other areas and, ultimately, moral hazard in intermediation. If it is impossible or impractical to separate the auditing of systems and risk management from the auditing of other activities, this approach may face difficulties. Letting technology leaders expand more rapidly into new products or geographic markets may provide an alternative way of compensating them for the expropriation of their technological improvements. An example of this type of expansion can be found in the case of J.P. Morgan, which in 1989 became one of the first commercial banks allowed to offer underwriting services. At the same time, Morgan was recognized as a market leader in credit-risk assessment through systems that later gave rise to CreditMetrics and similar risk-management tools.

To study this issue in more detail, suppose that regulators are unable to commit to a diffusion rate $\lambda<1$ so that all innovation becomes available to competitors. However, they can grant the innovating bank permission to enter new markets into which the technology has been disseminated. ${ }^{14}$ For simplicity, assume that the technology leader faces only one other bank in each market and that all competitors acquire the screening technology in period 2. At that time, bank 1 obtains permission to enter $n \geq 0$ new markets in addition to its original one so that, with a slight abuse

\footnotetext{
${ }^{13}$ We thank seminar participants at the FDIC for pointing out this fact.

${ }^{14}$ In principle, regulators could also allow the innovating bank to enter markets into which technology has not been disseminated, on the premise that the bank will eventually introduce an innovation in that market. Such policy, however, runs counter to regulatory concern over credit risk and does not seem appropriate, given that the precise terms of innovative activity, and consequently its results, are difficult to define.
} 
of notation, its ex ante expected net profits are now

$$
E\left[\Pi_{1}(n)\right]=\frac{1}{2}(2 \phi-1)-\left(\phi-\frac{1}{2}\right)^{2}+(n+1) \phi(1-\phi)(\bar{p} R-1)
$$

Maximization with respect to $\phi$ yields

$$
\phi_{n}^{*}=\frac{(n+1)(\bar{p} R-1)+2}{2+2(n+1)(\bar{p} R-1)}
$$

Simple differentiation of $\phi_{n}^{*}$ with respect to the number of additional market now yields

$$
\frac{\partial \phi_{n}^{*}}{\partial n}=-\frac{\bar{p} R-1}{2[1+(n+1)(\bar{p} R-1)]^{2}}<0
$$

Hence, allowing the technology leader to enter new markets reduces the level of financial innovation if regulators cannot commit to a sufficiently low rate of technological diffusion.

This somewhat surprising result again highlights the trade-off associated with the diffusion of technological progress. When technology developed by one bank becomes available to competitors, two effects operate. First, an increase in precision $\phi$ leads to more-efficient screening, which increases banks' profits. Second, with greater $\phi$ banks are subject to lower adverse-selection problems and therefore compete more aggressively for borrowers, thus reducing all banks' profits. Which effect dominates then depends on the strategic benefits of screening potential borrowers. If the technology leader has a monopoly on the use of the technological improvement, increases in $\phi$ raise bank 1's profits (gross of the cost of developing the technology). However, if bank 1 has to share its innovation with another lender, increases in screening quality $\phi$ beyond the threshold $\phi$ (see Proposition 3 ) reduce profitability because they engender too much competition. The technology leader would now benefit from reducing $\phi$ so as to limit competition.

It is precisely this latter effect that is at work in this instance. In our model, the profits earned by bank 1 in the first period alone would induce this intermediary to choose a level of precision for the technology that is optimal when it retains its monopoly over the technology but suboptimal if the technology disseminates to a competitor (i.e., $\phi_{n}^{*}>\underline{\phi}$ ). Now consider the effect of an increase in the number of markets in which bank 1 is active in period 2. The technology leader now faces competition in $n$ additional markets in which its competitors have access to the same screening 
technology. In each of these markets, bank 1 would benefit from reducing its investment in $\phi$. Moreover, the profits earned in these markets now represent a larger portion of the innovator's total profits. Therefore, as the number of additional markets increases, optimal investment $\phi_{n}^{*}$ falls as a way of softening the overall competition faced by bank 1 .

This result suggests that simply allowing banks more scope to expand their lending and explore new markets may not lead to lower portfolio risk because it increases the relative weight banks put on limiting competition. Since technology leaders achieve this outcome by reducing their investments in technology $\phi$, the net effect of entry into new markets is to reduce the quality of loans granted and increase overall banking-system risk.

Interestingly, profits for bank 1 do rise when it enters new markets, thanks to its increased scale. This outcome suggests that banks' objectives in terms of maximizing profitability through entry into new markets may also be in opposition to regulatory objectives of reducing risk. Hence, other mechanisms, such as the protection of intellectual property rights, might be necessary to compensate for the absence of clear commitment devices.

\subsection{Preventing Diffusion}

If regulators cannot credibly commit to allowing banks to retain their technological innovations in risk management, technology leaders face the threat of being unable to fully appropriate the gains from informational investments. In practice, we would expect banks to react by exerting effort to protect their property rights over innovations. Hence, we next investigate actions that intermediaries can take to directly protect their technology investments, and propose an alternative channel for intermediaries to assert property rights over their proprietary technology. ${ }^{15}$ We also discuss the role regulators may play in fostering or hindering these activities.

Suppose that bank 1 can exert costly effort $e \in[0,1]$ to prevent technological diffusion or expropriation. Such effort might include signing and enforcing confidentiality agreements with clients and employees, disguising the true extent of innovation from supervisors and regulators, and taking legal action against competitors to protect intellectual property. Let the diffusion

\footnotetext{
${ }^{15}$ As Wilhelm (2001) observes, advances in information technology have the potential to disrupt existing mechanisms for protecting intermediaries' property rights over information. Intermediaries therefore have an incentive to pursue alternative strategies that enforce their property rights and ensure an adequate return on their investments in innovation and information gathering.
} 
probability $\lambda$ be given by

$$
\lambda(e, t)=t(1-e), t \in[0,1]
$$

and assume now that regulators are able to choose $t$, which represents the probability that information technology disseminates across banks. In the absence of any preventive effort by bank $1(e=0)$, this specification is the same as in the preceding section: as $t$ increases toward $1, \lambda$ approaches complete dissemination. For $e=1$, no technological diffusion occurs $(\lambda=0)$, and the bank is able to retain proprietary use of any technology it develops.

As in the case of technological investments, we take effort costs to be quadratic: $\tilde{c}(e)=k e^{2}$ for $k>0$. Ex ante expected net profits of the technology leader are now

$$
E\left[\Pi_{1}\right]=(2-\lambda(e, t)) \frac{1}{2}(2 \phi-1)+\lambda(e, t) \phi(1-\phi)(\bar{p} R-1)-c(\phi)-\tilde{c}(e) .
$$

Bank 1 chooses investment $\phi$ and effort $e$ so as to maximize the preceding expression.

Proposition 5 In equilibrium, both $\phi^{*}$ and $e^{*}$ are strictly positive for all values of $t \in[0,1]$. Hence, even with a policy of complete dissemination $(t=1)$, overall diffusion rates are smaller than 1: $\lambda\left(e^{*}, 1\right)<1$.

Proof. See Appendix.

The proposition shows that, in equilibrium, technology leaders will wish to take steps to protect their intellectual property rights. If supervisory practices such as those proposed by the Basel II standards weaken the hold of innovators over proprietary risk-assessment innovations, one would expect technology leaders to allocate more resources to protecting their informational advantage. Moreover, regulators themselves might welcome such efforts as the patenting of financial innovations, which can be interpreted as allowing positive preventive effort in our model. We formalize this argument in the following result:

Proposition 6 For $t=1$, a marginal increase in the technology leader's effort toward preserving its proprietary technology reduces the banking system's loan-portfolio risk: $\left.\frac{d P^{2}}{d e}\right|_{e=0}>0$.

Proof. See Appendix. 
The proposition establishes that the marginal effect of an increase in effort $e$ is to reduce the aggregate portfolio risk of the banking system. Put differently, by letting banks invest resources in protecting their proprietary technology through, for instance, patenting, regulators are able to increase the overall loan-repayment probability in the banking system. At the margin, when regulators cannot commit to abstaining from expropriating the technology leader ex post, this added protection leads to greater technological improvements and thus a higher aggregate loan-portfolio quality. While bank 2 is less likely to obtain this new technology, its screening ability is improved when it does in fact gain access to the technology. The preceding result might also explain the tacit approval of protective practices by regulators, who have not stood in the way of intermediaries' patenting financial innovations, including IT advances, financial processes, and risk-assessment methodology. ${ }^{16}$

It is clear that the overall effect of protecting intellectual property rights on bank-portfolio risk depends on how easy it is for the technology leader to prevent technological diffusion. Although allowing banks to exert some effort in protecting their property rights may be beneficial, regulators may nevertheless prefer to strictly enforce their diffusion of best practices if preventive effort is not costly to bank 1 (small $k$ ). For instance, if preventive effort has no cost $(k=0)$, its optimal level is $e^{*}=1$ and no innovations are ever disseminated to competitor banks. Despite the strong incentive for innovation in this case, overall loan-portfolio quality will be lower since only the technology leader will benefit from the innovations.

The preceding discussion points to the fact that the extent to which regulators should encourage protective activities represents a trade-off between providing indirect incentives for innovation and reducing aggregate (system) risk. It also suggests that although regulators may wish to allow banks to protect intellectual property rights, they may also want to impose limits on banks' ability to prevent the diffusion of innovations. While in the context of the model such limits would naturally be interpreted as increases in the marginal cost $k$, in practice they may represent costs incurred in the process of patenting, limits on the life of financial patents, or commitments to audit more or less frequently so as to discover (and disseminate) banks' risk-management practices. ${ }^{17}$ Similarly,

\footnotetext{
${ }^{16}$ The data used in Lerner (2002) list 15 patents in the general area of credit-risk assessment and loan-application analysis granted between the years 1993 and 2000 alone (out of a total of 360 patents awarded for financial formulae or methods over the same period).

${ }^{17}$ A related approach is for regulators to advocate "standards of patentability" that would establish a minimum threshold for financial innovations to be patentable. Setting a high standard would be similar to increasing $k$ in our
} 
regulators might let banks patent their innovations but might then exert pressure on them to license advances in risk management. Innovators would now receive compensation from competitors or supervisory bodies through royalty payments or licensing fees.

\section{Discussion and Conclusion}

In this paper, we analyze some of the forces that shape financial innovation in the area of risk assessment, and we highlight the conflicting responsibilities of regulators in fostering and disseminating technological advances under the Basel II proposal. Although the new framework is explicit about the dissemination of best practices, it is silent on how to encourage the development of new technology in the first place. In particular, it does very little to address the inherent tension between Pillars 1 (risk-based capital-adequacy standards) and 3 (public disclosure of risks and their management) because enhanced transparency and the diffusion of technological progress hurt the profitability of the innovator. ${ }^{18}$

This tension between the ex ante incentives for innovation and the ex post dissemination of best practices to reduce bank risk is at the heart of our analysis. We show that regulators who minimize aggregate credit risk in the banking system will choose dissemination policies that leads to less than perfect and less than instantaneous access to innovations by competitors. However, such optimal diffusion of technological progress presupposes that regulators can credibly commit to protecting intellectual property rights of the innovating bank. If adequate commitment mechanisms do not exist or are not feasible, less innovation takes place, which increases the overall risk in the banking system. Regulators might then have an incentive to encourage banks to assert property rights over financial innovations through other means, such as financial patents.

Several empirical observations emerge from our analysis. In particular, we would expect the growing trend to patent financial processes and methodologies (see, e.g., Lerner, 2002, and 2004) to accelerate in the area of risk assessment and management under the Basel II framework. At the same time, the returns to such innovations should fall as they become more rapidly available to the industry. We may also see innovating banks receiving more-lenient regulatory treatment and

model. See Hunt (2003) for an analysis of the effect of a patentability standard on innovation.

${ }^{18}$ In the context of moral hazard in intermediation, Décamps, Rochet, and Roger (2003) identify similar tensions among the three pillars of the Basel II. 
experiencing less frequent audits as a way for supervisors to compensate them for the increased likelihood that their technology will become available to competitors.

An issue not studied here is the extent to which regulatory policy might coordinate not only the dissemination of new technology but also banks' activities. Suppose that prudential bank regulators enforce complete dissemination of technology but allow banks to carve up the market so as to retain monopoly power over a certain subset of borrowers. Such a policy of allowing banks to profit from their innovations may have effects similar to regulatory commitment to limit the extent of technological diffusion. However, we leave questions of industrial organization and the diffusion of financial innovation for future research.

Finally, we note that innovations and their diffusion typically occur in increments and over time so that this process has a clear dynamic dimension. Although our focus has been on the role of regulatory diffusion of financial innovation in a static setting, extending our model to a fully dynamic setting would yield interesting new insights on the pace and sequencing of financial innovations. A dynamic setting might also admit other mechanisms for commitment, such as allowing regulators to establish a reputation for adhering to announced dissemination policies. Such analysis, however, is beyond the scope of the present paper. 


\section{Appendix}

Proof of Proposition 1. Von Thadden (2001) or Hauswald and Marquez (2001) establish that pure-strategy equilibria do not exist in models such as ours. However, there exists a unique mixedstrategy equilibrium in interest-rate offers characterized by equilibrium distribution functions, $F_{1}$ and $F_{2}$, that are continuous and strictly increasing over an interval $[\underline{r}, R)$. Moreover, it is a standard result in models of competition under asymmetric information that a bidder, all of whose information is known by some other competitor, cannot make positive expected profits (see, e.g., Engelbrecht-Wiggans et al., 1983). Therefore, we can conclude that the uninformed lender, bank 2 , must make zero expected profits in equilibrium.

We will later verify that loan applicants with low credit-quality assessments $(\eta=l)$ will be denied credit, so that $p(l) R-1<0$, where $p(l)=(1-\phi) p_{h}$ represents the updated repayment probability of customers with a low-quality signal. This setting corresponds to a situation in which credit screens are sufficiently informative because of high-enough technology investments. ${ }^{19} \mathrm{We}$ can therefore restrict our attention to the case of high-quality signals, $\eta=h$.

To calculate profits for the informed bank, we proceed as follows: define $\pi_{2}(r)$ as the expected profit to the uninformed bank of offering an interest rate $r$. Since the uninformed bank must make zero profit for every one of its possible bids, it must make zero profits also at the lowest possible bid, $\underline{r}$. Offering that rate, the uninformed bank is guaranteed to have the lowest rate and win the bidding contest for a customer. Hence, $\pi_{2}(\underline{r})=0 \Leftrightarrow \underline{r} \bar{p}-1=0 \Rightarrow \underline{r}=\frac{1}{\bar{p}}$. Upon observation of a low signal $(\eta=l)$, the informed bank abstains from making a loan offer, and its profits are $\pi_{1}(l)=0$. However, upon observing a high signal $(\eta=h)$, the informed bank bids and obtains expected profits

$$
\pi_{1}(\underline{r}, h)=\underline{r} p(h)-1=\frac{1}{\bar{p}} p(h)-1 \equiv \bar{\pi}>0,
$$

where, for terminal cash flows $X, p(h) \equiv \operatorname{Pr}(X=R \mid \eta=h)=\phi p_{h}$ is the updated success (repayment) probability of a borrower with a high signal, and $\pi_{1}(r, h)$ represents the profits to the informed bank from offering a loan rate of $r$. Ex ante expected profits, which are $E\left[\pi_{1}(\eta)\right]=$ $\operatorname{Pr}(\eta=h) \pi_{1}(h)+(1-\operatorname{Pr}(\eta=h)) \pi_{1}(l)$, now follow directly by substituting for $\pi_{1}(l)=0$ and $\pi_{1}(h)$ from the above expression, and simplifying as $E\left[\pi_{1}(\eta)\right]=\frac{1}{2}(2 \phi-1)$.

Finally, the distribution functions can be obtained by solving the following expression for expected profit:

$$
\begin{aligned}
\pi_{1}(r, h) & =\bar{\pi}=\left(1-F_{2}(r)\right)(r p(h)-1) \\
\pi_{2}(r) & =0=\frac{1}{2}\left(1-F_{1}(r, h)\right)(r p(h)-1)+\frac{1}{2}(r p(l)-1)
\end{aligned}
$$

Substituting in for $\bar{\pi}$ and taking expectations yields the profit expression in the proposition; similarly, solving for $F_{1}$ and $F_{2}$ yields the (unique) mixing distributions $F_{1}(r, h)=2 \frac{\bar{p} r-1}{p(h) r-1}$ and $F_{2}(r)=2 \phi \frac{\bar{p} r-1}{p(h) r-1}$ on $\left[r_{\bar{p}}, R\right)$, where $r_{\bar{p}}=\frac{1}{\bar{p}}$ (for details, see Hauswald and Marquez, 2001). Notice that $F_{1}(R, h)<1$ and $\beta=F_{2}(R)<1$ so that bank 1 bids with an atom at the upper end of its support and consequently bank 2 refrains from bidding with probability $1-\beta$.

Proof of Proposition 2. Broecker (1990) establishes the nonexistence of a pure-strategy equilibrium for banks competing for borrowers on the basis of conditionally independent credit screens of

\footnotetext{
${ }^{19}$ This represents a restriction that $\phi>\underline{\phi}$, which is verified in equilibrium. See the proof of Proposition 3.
} 
the same informativeness. Let $F_{j}(r, \eta)$ be bank $j$ 's distribution function over interest rates $[\underline{r}, \bar{r}]$ for $\underline{r} \equiv \inf \left\{s: F_{j}(s, h)>0\right\}, \bar{r} \equiv \sup \left\{s: F_{j}(s, h)<1\right\}$ when they observe the credit-quality signal $\eta$. Since potential customers with low credit-quality assessments $\eta=l$ will be denied credit, we can again restrict our attention to the case of $\eta=h$. For credit screens of informativeness $\phi_{i}, \phi_{j}$, we get that bank $i$ 's profits from offering credit at interest rate $r$ after observing a high signal realization are

$$
\begin{aligned}
\pi_{i}(r ; h) & =\operatorname{Pr}\left(\eta_{j}=h \mid \eta_{i}=h\right)\left(1-F_{j}\left(r^{-}, h\right)\right)\left(p\left(h_{i}, h_{j}\right) r-1\right)+\operatorname{Pr}\left(\eta_{j}=l \mid \eta_{i}=h\right)\left(p\left(h_{i}, l_{j}\right) r-1\right) \\
& =\left(1-F_{j}\left(r^{-}, h\right)\right)\left(\phi_{i} \phi_{j}\left(p_{h} r-1\right)-\left(1-\phi_{i}\right)\left(1-\phi_{j}\right)\right) \\
& +\phi_{i}\left(1-\phi_{j}\right)\left(p_{h} r-1\right)-\left(1-\phi_{i}\right) \phi_{j}
\end{aligned}
$$

Since we are looking for a symmetric equilibrium, we have $\phi_{i}=\phi_{j}=\phi$ and $F_{i}(r, h)=F_{j}(r, h)=$ $F(r, h)$, so that the preceding expression simplifies to

$$
\pi_{i}(r ; h)=\left(1-F\left(r^{-}, h\right)\right)\left(\phi^{2}\left(p_{h} r-1\right)-(1-\phi)^{2}\right)+2 \phi(1-\phi)(\bar{p} r-1)
$$

Clearly, neither bank will ever offer (gross) rates higher than $R$, the project's payoff in the successful state so that $\bar{r}=R$. Similarly, it is straightforward to verify that the lower bound $\underline{r}$ is common so that both banks randomize over the full support $[\underline{r}, R)$. Furthermore, one can show that $F(r, h)$ is continuous and strictly increasing on $[\underline{r}, R)$ (see Hauswald and Marquez, 2001). Finally, in a symmetric equilibrium in which only borrowers with high credit quality obtain loans, both banks will always make an interest-rate offer if $\eta_{i}=h$ and neither bank can have an atom at the upper bound $R$. Evaluating $\pi_{i}(r ; h)$ at $R$ now yields expected profits conditional on the screening outcome for $p\left(h_{i}, l_{j}\right)=E\left[p \mid \eta_{i}=h, \eta_{j}=l\right]$ as

$$
\pi_{i}(R ; h)=\operatorname{Pr}\left(\eta_{j}=l \mid \eta_{i}=h\right)\left(p\left(h_{i}, l_{j}\right) R-1\right)=2 \phi(1-\phi)(\bar{p} R-1) \equiv \bar{\pi}
$$

Since the distribution function is strictly increasing on $[\underline{r}, R)$ we have that $\pi_{i}(r ; h)=\bar{\pi}$ for all $r \in[\underline{r}, R)$. Hence, we can recover the mixing distribution $F(r, h)$ using Equations (10) and (11), since $\pi_{i}(r ; h)=\bar{\pi} \Leftrightarrow$

$$
(1-F(r, h))\left(\phi^{2}\left(p_{h} r-1\right)-(1-\phi)^{2}\right)+2 \phi(1-\phi)(\bar{p} r-1)=2 \phi(1-\phi)(\bar{p} R-1)
$$

Solving for $F(r, h)$, this yields

$$
F(r, h)=\frac{\phi^{2}\left(p_{h} r-1\right)-(1-\phi)^{2}-2 \phi(1-\phi) \bar{p}(R-r)}{\phi^{2}\left(p_{h} r-1\right)-(1-\phi)^{2}}
$$

To find the lower bound of the support, we simply evaluate the numerator at $\underline{r}$ and observe that it has to be equal to 0 . Upon rearranging, we get

$$
\underline{r}=\frac{2 \phi(1-\phi)(\bar{p} R-1)+1}{\phi p_{h}}
$$

completing the characterization of the equilibrium.

To find the relevant signal-quality threshold $\phi$, note that for $p(l) R-1=(1-\phi) p_{h} R-1<0$, no bank will offer credit to a borrower deemed of low credit quality. Solving this expression with equality, we obtain $\underline{\phi}=\frac{p_{h} R-1}{p_{h} R}$. The ex ante profit expression in Equation (3) now follows by taking expectations in Equation (10), as in the proof of Proposition 1, and evaluating at $r=R$. 
Proof of Proposition 3. Maximization of bank 1's ex ante expected net profits in Equation (4), $E\left[\Pi_{1}\right]=(2-\lambda) \frac{1}{2}(2 \phi-1)-\left(\phi-\frac{1}{2}\right)^{2}+\lambda \phi(1-\phi)(\bar{p} R-1)$, with respect to $\phi$ yields $\phi^{*}=\frac{3+\lambda(\bar{p} R-2)}{2+2 \lambda(\bar{p} R-1)}$ from the FOC

$$
\frac{\partial E\left[\Pi_{1}\right]}{\partial \phi}=3-\lambda+\lambda(1-2 \phi)(\bar{p} R-1)-2 \phi=0
$$

Since $\lambda \in[0,1]$, we can always choose $\bar{p} R<M$, for sufficiently small $M$, such that the optimal investment is well defined, i.e., $\phi^{*} \in[\underline{\phi}, 1]$, where $\underline{\phi}=\frac{p_{h} R-1}{p_{h} R}>\frac{1}{2}$. The restriction that $\phi^{*} \geq \underline{\phi}$ ensures that an informed bank does profit from lending to a borrower with a low credit-quality assessment, or in other words, that $p(l) R-1<0$. One value for $M$ that guarantees that this restriction will be satisfied, so that borrower screening plays a role, is $M=2$, which represents an upper bound on average returns of $100 \%$.

Proof of Lemma 1. By the Law of Large Numbers, the post-screening repayment probability of bank 1's loan portfolio converges to its mean a.s. By Bayes' rule, the latter is given by

$$
p(h) \equiv \operatorname{Pr}(X=R \mid \eta=h)=\phi p_{h},
$$

for terminal cash flows $X$. Therefore, $\frac{\partial p(h)}{\partial \phi}=p_{h}>0$. By Corollary 1, we also have that $\frac{\partial \phi^{*}}{\partial \lambda}<0$, so that $\frac{\partial p(h)}{\partial \lambda}=\frac{\partial p(h)}{\partial \phi} \frac{\partial \phi^{*}}{\partial \lambda}<0$, as claimed.

Proof of Lemma 2. By Proposition 1, the probability that the uninformed bank (bank 2) submits a competing loan offer is $\beta=F_{2}(R)=2 \phi \frac{\bar{p} R-1}{p(h) R-1}$. We therefore have $\frac{\partial \beta}{\partial \phi}=-2 \frac{\bar{p} R-1}{(p(h) R-1)^{2}}<0$, since by assumption $\bar{p} R-1>0$. But then $\frac{\partial \beta}{\partial \lambda}=\frac{\partial \beta}{\partial \phi} \frac{\partial \phi^{*}}{\partial \lambda}>0$ as $\frac{\partial \phi^{*}}{\partial \lambda}<0$ by Corollary 1 .

Proof of Lemma 3. From the expressions in Equations (6) to (8), we find $\left.\frac{\partial P^{2}}{\partial \lambda}\right|_{\phi=c o n s t}=\tilde{p}-$ $\widehat{p}=(2 \phi-1) \frac{\left(\phi^{2}-\phi\right)(1-\beta)+\beta}{(2 \phi(1-\phi)+1)(1+\beta)} p_{h}$ so that $\beta>\left(\phi-\phi^{2}\right)(1-\beta)$ implies $\left.\frac{\partial P^{2}}{\partial \lambda}\right|_{\phi=c o n s t}>0$. However, since $\beta=\frac{\phi\left(\frac{1}{2} p_{h} R-1\right)}{\frac{1}{2}\left(\phi p_{h} R-1\right)}$, this condition is equivalent to $2\left(\frac{1}{2} p_{h} R-1\right)>(1-\phi)(2 \phi-1)$. Note that $(1-\phi)(2 \phi-1)$ is maximized at $\phi=\frac{3}{4}$ and obtains a value of $\frac{1}{8}$ for this value of $\phi$. Therefore, we require that $2\left(\frac{1}{2} p_{h} R-1\right)>\frac{1}{8} \Leftrightarrow \bar{p} R>1+\frac{1}{16}$. Letting $m=\frac{17}{16}$ satisfies this condition, establishing the result.

Proof of Proposition 4. To establish the result we differentiate $P^{2}$ with respect to $\lambda$ to obtain the first-order condition. Applying the chain rule, this yields

$$
\frac{d P^{2}}{d \lambda}=\frac{\partial P^{2}}{\partial \lambda}+\left(\frac{\partial P^{2}}{\partial \tilde{p}} \frac{\partial \tilde{p}}{\partial \phi}+\frac{\partial P^{2}}{\partial \widehat{p}} \frac{\partial \widehat{p}}{\partial \phi}\right) \frac{\partial \phi^{*}}{\partial \lambda}=0
$$

Since $\frac{\partial P^{2}}{\partial \lambda}=\tilde{p}-\widehat{p}, \frac{\partial P^{2}}{\partial \tilde{p}}=\lambda$, and $\frac{\partial P^{2}}{\partial \widehat{p}}=1-\lambda$, this reduces to

$$
\frac{d P^{2}}{d \lambda}=\tilde{p}-\widehat{p}+\left(\lambda \frac{\partial \tilde{p}}{\partial \phi}+(1-\lambda) \frac{\partial \widehat{p}}{\partial \phi}\right) \frac{\partial \phi^{*}}{\partial \lambda}=0
$$

Since $P^{2}$ is continuously differentiable with respect to $\lambda$ for $\lambda \in[0,1]$, in order to show that $0<\lambda^{*}<1$, we need two conditions: (i) $\left.\frac{d P^{2}}{d \lambda}\right|_{\lambda=0}>0$; and (ii) $\left.\frac{d P^{2}}{d \lambda}\right|_{\lambda=1}<1$. Starting with the case 
where $\lambda=0$, we need to show that

$$
\left.\frac{d P^{2}}{d \lambda}\right|_{\lambda=0}=\tilde{p}-\widehat{p}+\left.\frac{\partial \widehat{p}}{\partial \phi} \frac{\partial \phi^{*}}{\partial \lambda}\right|_{\lambda=0}>0
$$

Since $\phi^{*}(\lambda)=\min \left\{1, \frac{3+\lambda\left(\frac{1}{2} p_{h} R-2\right)}{2+\lambda\left(p_{h} R-2\right)}\right\}$, we have that $\phi^{*}(0)=1$, and $\left.\frac{\partial \phi^{*}}{\partial \lambda}\right|_{\lambda=0}=0$, so that the above condition becomes

$$
\left.\frac{d P^{2}}{d \lambda}\right|_{\lambda=0}>0 \Leftrightarrow \tilde{p}-\widehat{p}>0
$$

Using the definition of $\beta=\frac{\phi\left(\frac{1}{2} p_{h} R-1\right)}{\frac{1}{2}\left(\phi p_{h} R-1\right)}$ and since $\tilde{p}-\widehat{p}=(2 \phi-1) \frac{\left(\phi^{2}-\phi\right)(1-\beta)+\beta}{(2 \phi(1-\phi)+1)(1+\beta)} p_{h}$ (see proof of Lemma 3), this simplifies to $\tilde{p}-\widehat{p}=\frac{p_{h} R-2}{2 p_{h} R-3} p_{h}$, which, for $p_{h} R>2 \Leftrightarrow \bar{p} R>1$, is always positive. Hence, we establish that $\left.\frac{d P^{2}}{d \lambda}\right|_{\lambda=0}>0$ and, therefore, $\lambda^{*}>0$, as desired.

In the case for $\lambda=1$ we require that

$$
\left.\frac{d P^{2}}{d \lambda}\right|_{\lambda=1}=\tilde{p}-\widehat{p}+\left.\frac{\partial \tilde{p}}{\partial \phi} \frac{\partial \phi^{*}}{\partial \lambda}\right|_{\lambda=1}<0
$$

Again, we compute $\tilde{p}-\widehat{p}$ and note that $\phi^{*}(1)=\frac{\frac{1}{2} p_{h} R+1}{p_{h} R}$. It is useful to define at this point the variable $g=p_{h} R$, so that we can write $\phi^{*}=\frac{\frac{1}{2} g+1}{g}$, and observe that $\frac{\partial \phi^{*}}{\partial g}=-\frac{1}{g^{2}}<0$. We can now express the condition that $\left.\frac{d P^{2}}{d \lambda}\right|_{\lambda=1}<0$ as

$$
-\frac{1}{g^{3}} \frac{(g-1)\left(3 g^{5}-3 g^{4}+12 g^{3}+16 g^{2}-32 g-16\right)}{\left(g^{2}-2\right)\left(3 g^{2}-4\right)}<0
$$

which holds for $g>2$. But note that, in order for the market to support lending in equilibrium, we require that $\bar{p} R>1 \Leftrightarrow g>2$. Consequently, $\left.\frac{d P^{2}}{d \lambda}\right|_{\lambda=1}<0$, implying that $\lambda^{*}<1$, as desired.

Proof of Proposition 5. From the expected profit expression for the technology leader, we obtain the following first-order conditions:

$$
\begin{aligned}
& \frac{\partial E\left[\Pi_{1}\right]}{\partial \phi}=3-t(1-e)+t(1-e)(1-2 \phi)(\bar{p} R-1)-2 \phi=0 \\
& \frac{\partial E\left[\Pi_{1}\right]}{\partial e}=t\left(\frac{1}{2}(2 \phi-1)-\phi(1-\phi)(\bar{p} R-1)\right)-2 k e=0
\end{aligned}
$$

Using the definition of $\lambda=t(1-e)$, we can now solve for optimal investment as $\phi^{*}=\frac{3+\lambda(\bar{p} R-2)}{2+2 \lambda(\bar{p} R-1)}>\underline{\phi}$ for $0<\lambda<1$ (see Proposition 3). To show that the $e$ must be positive, we evaluate $\frac{\partial E\left[\pi_{1}\right]}{\partial e}$ at $e=0$ : $\left.\frac{\partial E\left[\pi_{1}\right]}{\partial e}\right|_{e=0}=t\left(\frac{1}{2}(2 \phi-1)-\phi(1-\phi)(\bar{p} R-1)\right)>0$ since bank 1 makes greater profits when it alone has access to the technology than when it must share it with bank 2 . Therefore, in equilibrium $e^{*}>0$, as desired.

Proof of Proposition 6. Recall our definition of $\lambda$ for the lack-of-commitment case:

$$
\lambda(e, t)=t(1-e), t \in[0,1]
$$


where lack of commitment means that $t=1$. We want to show that a marginal increase in $e$ reduces the banking system's loan-portfolio risk: $\left.\frac{d P^{2}}{d e}\right|_{e=0}>0$. Start by writing out this expression explicitly:

$$
\frac{d P^{2}}{d \lambda}=\frac{\partial P^{2}}{\partial e}+\frac{\partial P^{2}}{\partial \lambda} \frac{\partial \lambda}{\partial e}+\left(\frac{\partial P^{2}}{\partial \tilde{p}} \frac{\partial \tilde{p}}{\partial \phi}+\frac{\partial P^{2}}{\partial \widehat{p}} \frac{\partial \widehat{p}}{\partial \phi}\right) \frac{\partial \phi^{*}}{\partial e}
$$

Since there is no direct effect $\left(\frac{\partial P^{2}}{\partial e}=0\right)$, and recalling that $\frac{\partial P^{2}}{\partial \lambda}=\tilde{p}-\widehat{p}, \frac{\partial \lambda}{\partial e}=-t, \frac{\partial P^{2}}{\partial \tilde{p}}=\lambda$, and $\frac{\partial P^{2}}{\partial \widehat{p}}=1-\lambda$, this reduces to

$$
\frac{d P^{2}}{d e}=-t(\tilde{p}-\widehat{p})+\left(\lambda \frac{\partial \tilde{p}}{\partial \phi}+(1-\lambda) \frac{\partial \widehat{p}}{\partial \phi}\right) \frac{\partial \phi^{*}}{\partial e}
$$

Evaluated at $t=1$, we want to show that

$$
\frac{d P^{2}}{d e}=-(\tilde{p}-\widehat{p})+\left((1-e) \frac{\partial \tilde{p}}{\partial \phi}+e \frac{\partial \widehat{p}}{\partial \phi}\right) \frac{\partial \phi^{*}}{\partial e}>0
$$

for $e=0$. Substituting, this reduces to

$$
\left.\frac{d P^{2}}{d e}\right|_{e=0}=-(\tilde{p}-\hat{p})+\left.\frac{\partial \tilde{p}}{\partial \phi} \frac{\partial \phi}{\partial e}\right|_{e=0}>0
$$

Note now that, since $\frac{\partial \lambda}{\partial e}=-t=-1$, we obtain $\frac{\partial \phi}{\partial e}=\frac{\partial \phi}{\partial \lambda} \frac{\partial \lambda}{\partial e}=-\frac{\partial \phi}{\partial \lambda}$. This condition is equivalent to $-(\tilde{p}-\widehat{p})-\left.\frac{\partial \tilde{p}}{\partial \phi} \frac{\partial \phi}{\partial \lambda}\right|_{\lambda=1}>0$, which was established in the proof of Proposition 4 , so that $\left.\frac{d P^{2}}{d e}\right|_{e=0}>$ 0 , as desired. 


\section{References}

[1] Allen, F., J. McAndrews and P. Strahan (2002), "E-Finance: An Introduction," Journal of Financial Services Research 22: 5-27.

[2] Allen, L., G. DeLong and A. Saunders (2004), "Issues in the Credit Risk Modeling of Retail Markets," Journal of Banking and Finance 28: 727-752 .

[3] Akhavein, J., W. Frame, and L. White (2001), "The Diffusion of Financial Innovations: An Examination of the Adoption of Small Business Credit Scoring by Large Banking Organizations," forthcoming, Journal of Business.

[4] Anand, B. and A. Galetovic (2000), "Information, Nonexcludability, and Financial Market Structure," Journal of Business, 73: 357-402.

[5] Anton, J. and D. Yao (2002), "Little Patents and Big Secrets: Managing Intellectual Property," forthcoming, RAND Journal of Economics.

[6] Bank for International Settlements (BIS, 2003a), "The New Basel Capital Accord," Third Consultative Paper, Basel Committee on Banking Supervision, April 2003, available at http://www.bis.org/bcbs/bcbscp3.htm.

[7] Bank for International Settlements (BIS, 2003b), "Third Quantitative Impact Study," Basel Committee on Banking Supervision, May 2003, available at http://www.bis.org/bcbs/qis/qis3.htm.

[8] Benoît, J. (1985): "Innovation and Imitation in a Duopoly," Review of Economic Studies 52: 99-106.

[9] Bhattacharyya, S. and V. Nanda (2000), "Client Discretion, Switching Costs, and Financial Innovation," Review of Financial Studies 13: 1101-1127.

[10] Broecker, T. (1990), "Credit-Worthiness Tests and Interbank Competition," Econometrica 58 (2): 429-452.

[11] Décamps, J.-P., J.-C. Rochet, and B. Roger (2003), "The Three Pillars of Basel II: Optimizing the Mix," forthcoming Journal of Financial Intermediation.

[12] Engelbrecht-Wiggans, R., P. Milgrom, and R. Weber (1983), "Competitive Bidding with Proprietary Information," Journal of Mathematical Economics 11: 161-169.

[13] Hauswald, R. and R. Marquez (2001), "Competition and Strategic Information Acquisition in Credit Markets," mimeo, University of Maryland.

[14] Hauswald, R. and R. Marquez (2003), "Information Technology and Financial Services Competition," Review of Financial Studies 16: 921-948.

[15] Herrera, Helios and Enrique Schroth (2003), "Profitable Innovation Without Patent Protection: The Case of Derivatives," mimeo, ITAM and HEC Lausanne.

[16] Hirtle, B., M. Levonian, M. Saidenberg, S. Walter, and D. Wright (2001), "Using Credit Risk Models for Regulatory Capital: Issues and Options," Federal Reserve Bank of New York Economic Policy Review March 2001: 19-36. 
[17] Hunt, R. (2003), "Patentability, Industry Structure, and Innovation," Working Paper 01-13/R, Federal Reserve Bank of Philadelphia.

[18] Lerner, J. (2002), "Where Does State Street Lead? A First Look at Finance Patents, 19712000," Journal of Finance 57: 901-930.

[19] Lerner, J. (2004), "The New New Financial Thing: The Sources of Innovation Before and After State Street," NBER Working Paper 10223.

[20] Merton, R. (1995), "Financial Innovation and the Management and Regulation of Financial Institutions," Journal of Banking and Finance 19: 461-481.

[21] Mishkin, F. and P. Strahan (1999), "What Will Technology do to the Financial Structure?" in Robert Litan and Anthony Santomero, eds., The Effect of Technology on the Financial Sector, Brookings-Wharton Papers on Financial Services: 249-287.

[22] Reinganum, J. (1989), "The Timing of Innovation: Research, Development, and Diffusion," in R. Schmalensee and R. Willig, eds., Handbook of Industrial Organization, Vol. 1, Elsevier Science Publishers.

[23] Tirole, J. (1988), The Theory of Industrial Organization, MIT Press.

[24] Tufano, P. (1989): "Financial Innovation and First-Mover Advantages," Journal of Financial Economics 25: 213-240.

[25] Tufano, P. (2002), "Financial Innovation," in G. Constantinides, M. Harris, and R. Stulz, eds., Handbook of the Economics of Finance, North Holland.

[26] Van Horne, J. (1985), "Of Financial Innovations and Excesses," Journal of Finance 40: 621636.

[27] von Thadden, E.-L. (2001), "Asymmetric Information, Bank Lending and Implicit Contracts: The Winner's Curse," mimeo, Université de Lausanne.

[28] White, L. (1997), "Technological Change, Financial Innovation, and Financial Regulation: The Challenges for Public Policy," Working Paper 97-33, Wharton School Center for Financial Institutions, University of Pennsylvania.

[29] Wilhelm, W. (2001), "The Internet and Financial Market Structure," Oxford Review of Economic Policy 17: 235-247. 